\title{
Escritas de luz petrificadas
}

\section{Susan Blum Pessôa de Moura*}

\begin{abstract}
Resumo: Pretendo, neste artigo, analisar como uma Abstract: The focus of this paper is the analysis of obra literária pode revelar, de forma ficcional, a how a literary work can reveal, in a fictional way, the história e a memória de uma cidade (da humanidade) History and the memory of a city (of the humankind), através do saber de pedra. Clareando, objetivo through the stone knowledge. This analysis intends to promover um diálogo entre três artes - escultura, establish a dialogue among three arts - sculpture, fotografia e ficção - que buscam, através de formas um photography and fiction - which try, in different ways, tanto diferenciadas, a fixação da história em uma certa to set History into a certain memory. I use as source memória. Para tanto, aproveito o livro de Luis Alberto and reference, the book Saber de Pedra, written by Brandão chamado Saber de pedra, em que o autor Luis Alberto Brandão, in which the author collaborates colabora na memória da história de Belo Horizonte with the memory of the History of Belo Horizonte através das estátuas. Pedras estas trabalhadas não through statues whose stones are modified not only by somente pelos escultores como também pela oralidade the sculptures but by the orality of the city's inhabitants dos habitantes da cidade. as well.
\end{abstract}

Palavras-chave: história; memória; oralidade; escultura; fotografia.

Keywords: History; memory; orality; sculpture; photography.

\section{Introdução}

Saber de Pedra é um livro ímpar, Brandão alcança três objetivos ao entregar esta ficção ao leitor: 1. através das fotografias e das histórias das estátuas conhecemos um pouco mais sobre a memória e a história de Belo Horizonte; 2. através dos seus "ensaios" pensamos um pouco mais sobre o mundo; 3 . nos sentimos compelidos a ver e a pensar sobre as estátuas de nossa própria cidade. Ele cumpre, dessa forma, um dos papéis fundamentais da leitura: a busca pela história. Segundo Silva,

para a compreensão da história (individual ou social) a leitura exerce um papel de fundamental importância, pois que, sem a atribuição de significados aos fenômenos do mundo e às diferentes linguagens que o expressam, seríamos incapazes de nos situarmos no contexto social

\footnotetext{
* Doutoranda em Literatura na USP, instrutora da Fundação Cultural de Curitiba e professora da Faculdade Pequeno Príncipe. E-mail: susanpessoa@yahoo.com.br
} 
e buscarmos a verdade, ou seja, nosso crescimento enquanto seres humanos. Dessa forma, podemos, desde já, caracterizar a leitura como um processo ou prática social que permite à pessoa compreender a sua razão de ser no mundo, buscando, incessantemente, mais conhecimento sobre a realidade, seja observando diretamente a concretude do real, seja dando vida aos registros das culturas, expressos por meio de diferentes linguagens ou códigos. Mais especificamente, ler e compreender os objetos e/ou palavras é sempre uma tentativa de se compreender como um ser situado na história. (SILVA, 1991, p.75)

E é na leitura das estátuas e fotografias que esse escritor-observador, com suas hábeis mãos, cinzela a memória em histórias 'ficcionais' interessantes. Coloco escritor-observador porque é pelo olhar que apreendemos a arte, seja a escrita, a fotografia ou a escultura. Cada um de nós é um voyeur insaciável, que passeia os olhos despudoradamente sobre as palavras, as imagens e os simulacros, buscando respostas e identidades.

No livro o autor nos apresenta 18 (dezoito) estátuas da cidade de Belo Horizonte, através do ensaio fotográfico de Ronaldo Guimarães Gouvêa e das histórias antigas e 'verdadeiras' - e ainda através do uso da oralidade, com histórias cinzeladas pela boca do povo. Nelas, quem conta, aumenta um ponto - ou seria melhor dizer: quem conta insere uma pedrinha? Mas que não perdem o sabor por causa disto, pois como diziam as musas, filhas de Mnemosine : "Sabemos contar mentiras semelhantes às realidades; mas sabemos também proclamar verdades". E assim é a memória: seletiva e infiel. Basta recordar do poema Verdade de Drummond ${ }^{2}$.

A memória significa um acervo de perdas, de fatos passados, por vezes irrecuperáveis. É a memória que nos orienta no tempo, informa-nos sobre quem somos, de onde viemos e nos dá identidade. $\mathrm{O}$ homem inventa processos de registro para não ser refém do esquecimento. Entre esses registros encontramos as estátuas, as fotografias e os escritos. São eles que trazem de volta histórias quase enevoadas.

Esses registros, contudo, podem contar 'meias-verdades'. Tanto a história como as fotografias - tidas antigamente como reflexo ideal da realidade e hoje em dia vistas com um olhar mais desconfiado - podem ser meias-verdades. Digo isso não só por causa de programas como Photoshop. Também o digo pela "escolha" do fotógrafo - que tem um olhar ideológico por ser subjetivo - ou seja, toda escolha implica perda, opção e negação de algo.

Essa escolha também recai na escultura. Todo criador (seja escritor, fotógrafo ou escultor) faz suas opções. Assim como a pedra "mostra" ao escultor onde deve ser talhada, também a fotografia e a ficção 'dialogam' com o escritor-fotógrafo para a escolha das mesmas. Como disse Vasco Prado: "é a partir do desenho que a arte começa. É também o

\footnotetext{
1 as musas cantam no prelúdio da Teogonia (In: Revista História: Questões e Debates, nº 32, UFPR).

${ }^{2}$ Poema inserido nas epígrafes do artigo.
} 
desenho que determina a direção e as transformações da arte e fornece a possibilidade de repintar as idéias e concepções artísticas. O desenho é o ponto de partida para o esboço do quadro, da escultura ou de qualquer anotação clássica” (RUIZ, 1984, p.26). O esboço, a idéia e os rascunhos são, desse modo, os primeiros diálogos entre obra e autor.

Para que possamos realizar uma análise mais profícua, vamos abordar em separado cada uma das artes.

\section{Assim não era possível atingir toda a verdade, porque a meia pessoa que entrava só trazia o perfil de meia verdade. \\ E sua segunda metade voltava igualmente com meio perfil. E os meios perfis não coincidiam. (Verdade, Drummond, 1987, p.41)}

\section{Estátuas}

As imagens são uma forma de preservar a memória. No início eram feitas com inscrições e epigrafias e depois, principalmente no Oriente antigo, com monumentos (como estelas e obeliscos). O início da representação humana em estátuas vem dos egípcios, por uma questão religiosa ( $c f$. LE GOFF, 1994, p.431). Já o mundo greco-romano utilizava muito mais as pedras e os mármores como suporte de sobrecarga da memória: "Os arquivos de pedra acrescentavam à função de arquivos propriamente ditos um caráter de publicidade insistente, apostando na ostentação e na durabilidade dessa memória lapidar e marmórea” (LE GOFF, 1994, p.432).

Com a valorização da visualidade e com a interação mais humana, as estátuas descem dos pedestais e interagem com a sensibilidade humana. Elas se diferenciam, assim, dos monumentos, que geralmente comemoram algum personagem, feito ou acontecimento. Mas todos eles acabam por fazer parte da memória e da história de um povo e de uma cultura, seja pela história que trazem em si, seja pelo fato de se inserirem na História pelo escultor ou pela história de construção ou edificação. Assim, memorial e, portanto, espacialmente, fazem rememorar algum fato pregresso e espacializam a nossa memória.

Eles, monumentos e estátuas, inserem-se na paisagem. A estátua, em princípio um monumento frio e distante, é aproximada do contato humano e justamente por ser estática (em um mundo fragmentado, dinâmico e com visualidade fast-food) não chama a atenção dos transeuntes, que muitas vezes passam por elas sem ao menos notá-las. Mas Brandão alerta este nosso olhar, nos faz curiosos de conhecer os protagonistas dessas histórias, trazendo 
algumas histórias verdadeiras e outras ficcionais.

Afinal, nenhuma escultura é inserida neste mundo urbano sem um objetivo claro. Como já alertou Cacá Brandão em seu artigo Arquitetura e Filosofia, há uma filosofia e um social por trás de cada imagem ou simulacro:

Uma pólis se faz, enquanto corpo cívico e político, ao mesmo tempo em que constrói o seu lugar, sua urbs, seu corpo físico. Uma sociedade se conhece e se reconhece mediante o que ela realiza como obra e se coloca como produto de si. Cidades, praças, ruas, prédios, monumentos, casa e objetos decorativos que neles colocamos não são como objetos gratuitos ou ornamentações, mas instrumentos de conhecimento e reconhecimento, de encontro com as próprias certezas e dúvidas, com a própria história, princípios, valores e desejos que elegemos para termos em torno de nós, enquanto indivíduos e sociedade: e só assim concebidos têm eles "decoro" ou "archê" e incorporam-se ao nosso "patrimônio". Eles ornamentam e decoram nossa vida, não por a emoldurarem, como uma beleza acrescida ou extrínseca - ornamentações e decorações - mas por serem constituintes de nós mesmos, por construir-nos simultaneamente ao nosso ato de construí-las. (BRANDÃO, 2006, p.05)

Nessa eleição da história, princípios e valores que buscamos em cada escultura também são buscados pelos próprios escultores, dentro deles e na história. Todos eles sabem, e tomo aqui a palavra de Vasco Prado, que "é preciso indagar, experimentar, saber a arte do passado para descobrir a nova, já que somos históricos: continuamos, mesmo quando inovamos e inventamos" (apud RUIZ, 1984, p.14). Ou seja, a história já está presente antes mesmo da concepção da estátua. A continuidade ou, ao contrário, o experimentalismo nas artes solicitam pesquisa e absorção dos antigos elementos.

Contudo, para percebermos estas nuances, necessitamos de uma reeducação dos sentidos, uma aprendizagem na leitura de imagens e um olhar mais cuidadoso à história das artes plásticas. Não basta encontrar os "simulacros adequados das coisas que se deseja recordar", que é, aliás, uma das regras mnemônicas de Tomás de Aquino (cf. LE GOFF, 1994, p.455). É necessário ter o conhecimento que se associa a este simulacro, ou, como outra regra de Aquino, "meditar com frequiência no que se deseja recordar". De nada adianta, então, ver as estátuas ou fotos, se não se medita sobre a história que as envolve. Em um dos ensaios de Saber de Pedra encontramos o seguinte questionamento:

Costuma-se afirmar que as estátuas têm o poder de contar o passado da cidade. Essa afirmativa só é válida se pensamos que elas ocupam muitos presentes, os quais se oferecem como pontos a interligar de inúmeras formas, produzindo uma variedade de passados possíveis. A estátua é um estímulo à maleabilidade temporal. Um incentivo para que a história da cidade seja, constantemente, renarrada (Brandão, 1999, p.45).

Arrebentaram a porta. Derrubaram a porta.

Chegaram ao lugar luminoso onde a verdade esplendia seus fogos.

Era dividida em metades diferentes uma da outra. 
(Verdade, Drummond, 1987, p.41)

\title{
3 Fotografia
}

Segundo o mito, na origem da palavra imagem encontra-se a ausência, a nostalgia e a separação de corpos. No livro de Brandão as estátuas são presença através das fotografias que aproximam os corpos. Uma proximidade, mesmo que apenas pelo olhar do fotógrafo, das estátuas de Belo Horizonte para outros espectadores - como nós de Curitiba. Em um paradoxo, a fotografia aproxima e afasta, pois não temos a oportunidade de circundar por nós mesmos as estátuas, escolher que direções nosso olhar deve seguir, sentir o seu cheiro, ver seu entorno, tocar em sua pedra áspera ou lisa, fria ou quente, ouvir os sons que as cercam ou que elas produzem.

Como visto, a fotografia é uma escolha e, portanto, nos fecha a percepção apenas em seus limites, a 'verdade' não pode ser degustada apenas através das artes.

As imagens fotográficas não se esgotam em si mesmas, pelo contrário, elas são apenas o ponto de partida, a pista para tentarmos desvendar o passado. Elas nos mostram um fragmento selecionado da aparência das coisas, das pessoas, dos fatos, tal como foram (estética/ideologicamente) congelados num dado momento de sua existência/ocorrência. (KOSSOY, 2002, p.21)

Uma vez considerada apenas pistas, devemos recordar que a fotografia tem uma realidade própria que não corresponde necessariamente à realidade que envolveu o assunto, objeto do registro, no contexto da vida passada: ela tem uma segunda realidade construída, decodificada e sedutora em sua montagem, no entanto,

\begin{abstract}
a imagem fotográfica é fixa, congelada na sua condição documental. Não raro nos defrontamos com imagens que a história oficial, a imprensa, ou grupos interessados se encarregaram de atribuir um determinado significado com o propósito de criarem realidades e verdades. Cabe aos historiadores e especialistas no estudo das imagens, a tarefa de desmontagem de construções ideológicas materializadas em testemunhos fotográficos (KOSSOY, 2002, p.22).
\end{abstract}

A realidade na foto pode ser fixa e imutável, mas é sujeita a múltiplas interpretações. Aliás, nos textos também encontramos uma trama interesseira. No caso de Brandão, se percebe claramente o ressentimento pela modernidade que se desvencilha tão rapidamente da história, do antigo e do tradicional, ao invés de dialogarem amigavelmente.

Para dar às estátuas um 'espaço' mesmo que virtual, o autor incluiu um ensaio fotográfico que permitiu a viagem virtual dessas esculturas até outras cidades. E elas chegam a outras cidades, para olhares curiosos de cidadãos leitores que talvez, ao visitarem Belo Horizonte, não as vissem ou nem sequer conhecessem suas histórias. 
Chegou-se a discutir qual a metade mais bela. Nenhuma das duas era totalmente bela.

E carecia optar. Cada um optou conforme seu capricho, sua ilusão, sua miopia. (Verdade, Drummond, 1987, p.41)

\section{Ficção}

Pierre Janet (1994) considera o comportamento narrativo um ato mnemônico fundamental, que se caracteriza pela função social. É a comunicação a um outro, de uma informação, na ausência do acontecimento ou do objeto que constitui seu motivo. A linguagem, tanto a falada quanto a escrita, é um produto da sociedade que serve para armazenamento da memória (cf. JANET apud LE GOFF, 1994, p.424).

Brandão nos apresenta, por meio da narrativa, uma Belo Horizonte carregada de simbolismos e de graça, mas também de tristeza pelo vandalismo. O vandalismo nas estátuas é como uma metáfora da história que também pode ser "arrebentada" nas letras e entrelinhas dos escritos históricos. Procura-se sublevar a transitoriedade do ser humano, através das artes. "Narro para intensificar a sensação de pertencer a um tempo. E para produzir a ilusão de que posso evitar minha transitoriedade" (BRANDÃO, 2001, p.54).

No entanto, sabe-se que tudo é transitório, até mesmo um patrimônio material em princípio 'infinito'. O que realmente importa é o patrimônio imaterial, a cultura, a história, a memória do outro. Que seja infinito enquanto dure; e mesmo após a sua duração, que permaneça a história. Em uma época em que a alteridade está presente, Brandão faz o diálogo com o outro, ou melhor, diálogo pelo outro. Pelo outro que não tem voz, dando-lhe essa voz mineralógica não tão lógica ou, por vezes, até mais do que lógica.

Desse modo, o texto poético de Brandão traz o surgimento da voz dentro do mutismo dos signos, dando um valor espacio-temporal à linguagem no qual. Aproveito uma fala de Gonçalves ao abordar o pictural em Proust:

ao mesmo tempo que nos prende ao circuito da folha de papel, nos remete para frente, temporalmente, dentro da instância delineada pela moldura mítica. Assim, o poema consiste num caminhar dentro de si mesmo, dentro de um novelo tensionado pela condição de duração em que a memória voluntária e memória involuntária se degladiam na busca do diagrama da recordação. (GONÇALVES, 2004, p.147)

E as histórias contadas por BRANDÃO (2001) trazem (independentemente de o leitor ser mineiro ou não) essa busca pela História das esculturas citadas. Muitas memórias são suscitadas dentro do leitor, que promove associações a outras histórias de outras esculturas, 
presentes ou não, em sua vida.

Se, como BERGSON procurou conceituar, "o homem é o que tem de si” (1999, p. 31), tanto as estátuas, quanto as fotografias e a literatura são pertencentes ao ser humano. Pode-se admirar as estátuas apenas por elas mesmas, mas também pode-se procurar saber de suas histórias (de criação, de objetivo, de existência, de "morte") e assim conhecermos a nós mesmos como seres humanos pertencentes a uma cultura. Brandão nos apresenta essa memória através de um processo de bricolagem, em que a memória sensível promove uma espécie de superposição de imagens articuladas de esculturas/fotografias e histórias em um movimento entre arte e realidade, entre estética e ética.

É como se as estátuas/fotos fossem fragmentos, imagens desgarradas que posam diante do sujeito de memória e que constituem índices de um espaço-tempo perdido, que também é espaço-tempo que se descobre.

Brandão aproveita as falas dos cidadãos que convivem com as estátuas e isso nos remete ao fato de que, segundo LE GOFF (1994), tanto a memória quanto o esquecimento são manipulados, conscientemente ou inconscientemente, pelos: interesse, afetividade, desejo, inibição e censura ( $c f$. LE GOFF, 1994, p.426). Neste sentido LE GOFF (1994) alerta que "Tornarem-se senhores da memória e do esquecimento é uma das grandes preocupações das classes, dos grupos, dos indivíduos que dominaram e dominam as sociedades históricas. Os esquecimentos e os silêncios da história são reveladores desses mecanismos de manipulação da memória coletiva.” (LE GOFF, 1994, p.426).

A memória das esculturas de Belo Horizonte foi de interesse do autor, que, com afetividade e desejo, revelou histórias que contêm inibição e censura. Brandão teve como objetivo não a manipulação, mas o questionar dentro da leitura. O leitor não fica indiferente às histórias contadas - e a memória das estátuas vai variar dentro do leitor justamente pela afetividade e interesse que cada um vai ter. Contudo, nenhuma ficará impune de estar, de alguma forma, dentro do indivíduo, assim como estavam dentro dos moradores da cidade de Belo Horizonte.

Segundo NADEL, há dois tipos de História: a história objetiva, que é "a série dos fatos que nós, investigadores, descrevemos e estabelecemos com base em certos critérios 'objetivos' universais no que diz respeito às suas relações e sucessão"(apud LE GOFF, 1994, p.400) E a história ideológica, "que descreve e ordena esses fatos de acordo com certas tradições estabelecidas". Esta é a que tende a confundir a história e o mito ( $c f$. LE GOFF, 1994, p.428). No livro Saber de Pedra, BRANDÃO (1999) nos apresenta as duas histórias, pois mescla, tal como no mármore que possui claros e escuros, ensaios e ficção. O livro é 
dividido em páginas claras e escuras, trazendo teorias, ensaios e conhecimentos sobre as esculturas e narrativas ficcionais com senso de humor, sarcasmo e cumplicidade.

Ao dar voz às estátuas, elas mesmas afirmam a plurivisão das coisas, elas mesmas questionam as verdades e a História, mostrando facetas despercebidas, ou não questionadas. Um exemplo está na história dos três ideólogos, em que um deles diz que seu "compromisso é com a verdade" (BRANDÃO, 1999, p.78) e relata três histórias como "verdade integral". O segundo ideólogo já inicia a fala com: "Histórias são inúmeras, e variados os sentidos que lhes atribuímos. Venho observando, há tempos, a rotina da cidade e sou descrente de que suas histórias podem ser compartilhadas, de que pode haver consenso sobre seu significado" (BRANDÃO 1999, p. 79). Ele conta as mesmas histórias, mas não se coloca como autoridade e se exime de qualquer julgamento. Apresenta a "dúvida". E o terceiro, por sua vez, revisita as histórias:

Adoro revisitar episódios de nossa história. Através deles nos reconhecemos no passado, e sentimos que a vida não é um conjunto de fatos isolados, mas uma linha contínua. Conto histórias para defender nossos valores mais caros, e para reavivar a direção do caminho a seguir (BRANDÃO, 1999, p.81).

E continua, logo em seguida:

Voltarmo-nos para a história, atentos aos fatos do passado, é a melhor forma de estarmos seguros de que são sensatas as decisões do presente. Em cada acontecimento de nossa existência, mesmo nos mais terríveis, podemos encontrar uma lição. Isso é válido não apenas para indivíduos, mas para a humanidade como um todo. Para isso servem as instituições: para extrair e preservar as lições que a vida em sociedade oferece (BRANDÃO, 1999, p.82).

Essa última escultura não pensa na verdade ou na dúvida daquelas mesmas histórias, mas mostra a importância do "compromisso" e da "responsabilidade".

Várias outras estátuas contam outras histórias e outras memórias, incluindo personalidades como Juscelino Kubitscheck, Tancredo Neves, Pampulha, etc. Mas isso é material para um outro trabalho.

Por muito tempo achei que a ausência é falta.

E lastimava, ignorante, a falta.

Hoje não a lastimo.

Não há falta na ausência."(Ausência, Drummond, 1987, p.25)

\section{$5 \mathrm{O}$ diálogo entre as três artes}

A estátua, assim como a foto, traz um prolongamento de contato ou proximidade. Entretanto, traz, principalmente, a possibilidade de reflexão sobre seu significado, como a 
escrita. Cada monumento ou estátua têm o seu objetivo e sua história, seja para homenagear alguém ou algum acontecimento. A fotografia traz uma proximidade da escultura, mas ela não abarca toda a realidade, pois a estátua não é apenas a peça em si: ela é também é o seu entorno. Pois as esculturas não são inseridas aleatoriamente em qualquer local, o circundante também faz parte dessa história. Brandão, com a narrativa, supre isso de alguma forma, descrevendo a localização de algumas das estátuas/esculturas. Assim, as artes expostas apresentam semelhanças e diferenças. Algumas delas foram expostas por Kubrusly:

a palavra é racional, dissertativa, prolixa. A imagem, emocional, sintética, direta. A palavra pode expor com clareza uma idéia, conceituar com precisão. A imagem é de natureza mais onírica [...], mais ilógica e nebulosa. É insubstituível para transmitir, num relance, toda a emoção de um evento, mas falha ao tentar analisá-lo (KUBRUSLY, 1998, p.77).

Nas três artes temos relevâncias, como: na ausência do amado, a moça apaixonada procura abolir o tempo; na presença da estátua no livro, Luis Alberto (1999) procura abolir as fronteiras espaciais, fazendo-nos habitantes desse mundo de pedra. Já o tempo, ele deixa correr, como se percebe no caso "A voz", em que apenas a base da estátua e a história da escultura estão presentes. Propositadamente não foi escolhida uma fotografia antiga dela, mas sim a ausência (ou deveria dizer presença?) atual, denunciando a violência. É um espaço agora ocupado pela ficção, pois 'Ser é estar', afirma BRANDÃO (1999). Servindo assim, mais do que nunca, para a reflexão do passado/ presente/ futuro da humanidade. Estamos? Somos? Se tudo que é sólido se desmancha no ar, o que será do ser humano que também está sujeito à violência urbana?

A busca da memória até mesmo nas ruínas, esse ir e vir da recordação, esse deslindar do tempo que nos conduz ao aprendizado de nós mesmos fazem com que se metamorfoseiem em nós, aspectos que jamais assumiríamos como mutáveis. Promovem uma busca na memória até mesmo daquilo que não vivemos. A verdade passa a ser questionada, aprendemos que existem pontos de vista e que a história é uma multiplicidade.

Podemos nos questionar se as narrativas do livro são verdadeiras. Mas isso é realmente importante? Pois a própria História, tida antigamente como a 'verdade' e o 'certo', hoje em dia é questionada por também ser um leque de pontos de vista. Por isso, em uma pequena imitação de física quântica, concordo com o que PIGLIA afirmou certa vez: "a história é a proliferação retrospectiva dos mundos possíveis" (1986, p.68). Afinal, como nos alerta KOSSOY, algumas imagens nos levam a rememorar, outras a moldar nosso comportamento; ou a consumir algum produto ou serviço; ou a formar conceitos ou reafirmar pré-conceitos que temos sobre determinado assunto; outras despertam fantasias e desejos (Cf. 2002, p.44-5). 
A escultura e a fotografia não existiriam como forma de linguagem se não se fizessem linguagem na mente do observador. As representações delas dependem muito do olhar mental daqueles que as lêem ou a 'escrevem'.

A ausência é um estar em mim. E sinto-a, branca, tão pegada, aconchegada nos meus braços, que rio e danço e invento exclamações alegres, porque a ausência, essa ausência assimilada, ninguém a rouba mais de mim. (Ausência, Drummond, 1987, p.25)

\section{Leitura de mundo}

Sintetizando, temos conhecimento de que em qualquer arte há a interferência tanto do autor (no processo de construção da representação) quanto do leitor/espectador (no processo de construção da interpretação). Em Saber de Pedra vemos que o escultor construiu uma representação, que foi reconstruída pelo fotógrafo e também pelo escritor. E que, por sua vez, é reconstruída pelo leitor. Portanto, conhecer, estudar e, principalmente, questionar e verificar as várias possibilidades de "respostas" são alguns dos objetivos de qualquer educador que deseja formar verdadeiros leitores; não alfabetos funcionais, mas cidadãos conscientes. Porque é o cidadão que conhece a sua história, a sua memória e sabe fazer uma leitura de mundo, que pode participar de forma mais consciente e ativa da sociedade.

[...] O esquecimento insensível e ingrato que se abate sobre a maioria das pessoas e se apossa delas [...] quebra a unidade da vida proveniente de que o passado mistura-se ao presente; ao contrário, [...] o esquecimento faz que todo acontecimento não tenha acontecido para aquele que dele não se lembra [...] aqueles que não preservam nem evocam, graças à memória, os acontecimentos anteriores, mas os deixam escapar, tornam-se a cada dia vazios e indigentes... (SIMONDON,1964, p.305)

Poderíamos dizer que aqueles que passam pelas estátuas e não as vêem, ou aqueles que passam por elas, mas não conhecem sua história como memória da cidade, se tornam cada vez mais petrificados em sua ignorância. BRANDÃO (1999), em seu livro, com as fotografias e a ficção, traz para perto do cidadão comum, as histórias caladas das estátuas mudas.

No entanto, ao mesmo tempo, como se percebe pela oralidade do povo em relação às esculturas, pode-se aproveitar as duas últimas epígrafes deste artigo, que apresentam “Ausência”, de Drummond. Revelando que a ausência está dentro de nós, pode-se não saber a história real/verdadeira (o que é questionável, como já visto), porém se tem conhecimento das histórias que perpassam a história da própria escultura e ela está na memória de cada um, grudada, incrustada tal qual líquen na pedra antiga. 
Assim, todas as três artes permitem um diálogo aberto com o leitor/espectador. Um diálogo diferenciado, de pessoa a pessoa, de cultura a cultura e que também varia de um tempo para outro. Aproveito aqui uma fala quase ao final do livro Matéria e Memória, em que BERGSON afirma:

Mas um ser que evolui mais ou menos livremente cria a todo instante algo de novo: é portanto em vão que se buscaria ler seu passado em seu presente se o passado não se depositasse nele na condição de lembrança. Assim, para retomar uma metáfora que já apareceu várias vezes neste livro, é preciso, por razões semelhantes, que o passado seja desempenhado pela matéria, imaginado pelo espírito. (BERGSON, 1999, p.262)

E Brandão logra justamente isso: as estátuas e as fotografias desempenham o passado, e a ficção o imagina. Finalizo salientando a importância da leitura de mundo e de vida, que contribuirá para a memória e para a história e vice-versa, em um ciclo de co-existência. Nesse sentido, aproveito mais uma vez o texto de LE GOFF: "a memória, onde cresce a história, que por sua vez a alimenta, procura salvar o passado para servir o presente e o futuro. Devemos trabalhar de forma a que a memória coletiva sirva para a libertação e não para a servidão dos homens" (1994, p.477).

\section{Anexo 1}

\section{VERDADE}

A porta da verdade estava aberta, mas só deixava passar meia pessoa de cada vez.

Assim não era possível atingir toda a verdade, porque a meia pessoa que entrava só trazia o perfil de meia verdade. E sua segunda metade voltava igualmente com meio perfil. $\mathrm{E}$ os meios perfis não coincidiam.

Arrebentaram a porta. Derrubaram a porta.

Chegaram ao lugar luminoso onde a verdade esplendia seus fogos. Era dividida em metades diferentes uma da outra.

Chegou-se a discutir qual a metade mais bela. Nenhuma das duas era totalmente bela. E carecia optar. Cada um optou conforme seu capricho, sua ilusão, sua miopia. 
(Verdade, Drummond, 1987, p.41)

\title{
8 Anexo 2
}

\author{
Ausência. \\ Por muito tempo achei que a ausência é falta. \\ E lastimava, ignorante, a falta. \\ Hoje não a lastimo. \\ Não há falta na ausência. \\ A ausência é um estar em mim. \\ E sinto-a, branca, tão pegada, aconchegada nos meus braços, \\ que rio e danço e invento exclamações alegres, \\ porque a ausência, essa ausência assimilada, \\ ninguém a rouba mais de mim.
}

(Ausência, Drummond, 1987, p.25)

\section{Referências}

ANDRADE, Carlos Drummond de. Corpo. Rio de Janeiro: Record, 1987.

BAKHTIN, Mikail. Marxismo e Filosofia da Linguagem. São Paulo: Hucitec, 1979.

BERGSON, Henri. Matéria e Memória. São Paulo: Martins Fontes, 1999.

BERMAN, Marshall. Tudo que é sólido desmancha no ar. São Paulo: Cia das letras, 1998.

BRANDÃO, Luis Alberto. Saber de Pedra- o livro das estátuas. Belo Horizonte: Autêntica, 1999. . Sujeito, tempo e espaço ficcionais. São Paulo: Martins Fontes, 2001.

. Um olho de vidro: A narrativa de Sérgio Sant'Anna. Belo Horizonte: Ufmg/fale, 2000 .

Brandão, Carlos Leite (Cacá). Arquitetura e Filosofia. In: Suplemento. Belo Horizonte, jan $2006, n^{\circ} .1286$.

GONÇALVES, Aguinaldo J. Museu movente. São Paulo: UNESP, 2004.

História. Questões e debates. Ano 17, N. 32. Brasil. A conquista do olhar. Curitiba: ed. UFPR, 2000.

KOSSOY, B. Realidade e ficções na trama fotográfica. São Paulo: Ateliê ed., 2002. 
KUBRUSLY, C. O que é fotografia. São Paulo: Brasiliense, 1998.

LE GOFF, Jaques. História e Memória. Campinas: Unicamp, 1994.

MANGUEL, Alberto. Lendo imagens. São Paulo: Cia das Letras, 2001.

NOVAES, Adauto. (org.) O olhar. São Paulo: Cia das Letras, 2002.

PIGLIA, Ricardo. Crítica y ficción. Santa Fé: Universidad nacional del litoral, 1986.

RUIZ, Horacio. Vasco Prado. RS/SP: Iochpe, 1984.

SILVA, E.T. De olhos abertos. Reflexões sobre o desenvolvimento da Leitura no Brasil. São Paulo: Ática, 1991.

SIMONDON, Gilbert. L'individu et sa genèse physico-biologique. P.U.F., Paris, 1964. 